\title{
COMUNICAÇÃO
}

\section{QUALIDADE E VIDA DE PRATELEIRA DE BANANA 'PRATA' MINIMAMENTE PROCESSADA}

\author{
Quality and shelf life of fresh-cut banana 'Prata' \\ Camila Martins Fonseca Reis ${ }^{1}$, Eduardo Valério de Barros Vilas Boas ${ }^{2}$, \\ Cleube Andrade Boari ${ }^{3}$, Roberta Hilsdorf Píccoli ${ }^{4}$
}

\begin{abstract}
RESUMO
Neste trabalho estudou-se o efeito da mistura química (cloreto de cálcio + ácido ascórbico + L-cisteína) e da atmosfera modificada ativa na qualidade e vida de prateleira de banana 'Prata' minimamente processada. As variáveis acidez total titulável, perda de massa e açúcares solúveis totais apresentaram aumentos significativos ao longo do período de armazenamento. Os valores de sólidos solúveis totais apresentaram aumento significativo ao longo do tempo, e a mistura química com 0,5\% de L-cisteína determinou os maiores valores dessa variável. Com os valores obtidos nas análises microbiológicas, pode-se constatar a ausência de coliformes totais e fecais e baixos valores de fungos filamentosos, leveduras e microrganismos aeróbios mesófilos.
\end{abstract}

Termos para indexação: Minimamente processado, atmosfera modificada, L-cisteína, ácido ascórbico, cloreto de cálcio.

\begin{abstract}
The objective of this work was to evaluate the effect of a chemical dip (calcium chloride + ascorbic acid + L-cysteine) and modified atmosphere on the quality and shelf-life of fresh-cut 'Prata' banana. The variables titratable acidity, mass loss and total soluble sugars increased significantly over the storage period. An increase in total soluble solids was observed over the storage period, whereas the chemical dip with $0,5 \%$ of L-cysteine promoted the highest values of that variable. The microbiological analysis did not detect fecal and total coliforms, although have detected low levels of mesophilos aerobics, fungus and yeast.
\end{abstract}

Index terms: Fresh-cut, modified atmosphere, L-cysteine, ascorbic acid, calcium chloride.

(Recebido para publicação em 16 de dezembro de 2002 e aprovado em 18 de setembro de 2003)

O produto minimamente processado apresenta características mais próximas da forma "in natura", comparado aos produtos processados de forma convencional. Os frutos minimamente processados ou "freshcut" são submetidos a operações de limpeza, lavagem, seleção, descascamento e corte, até chegarem a um produto $100 \%$ aproveitável, que é embalado a fim de oferecer aos consumidores frescor, conveniência e qualidade nutricional (SHEWFELT, 1986; IFPA, 2002).

A aplicação de tratamentos químicos no fruto, como ácido ascórbico, cloreto de cálcio e cisteína, produtos reconhecidos como seguros e liberados para o uso como aditivos alimentares (ANVISA, 2003), e o uso de atmosferas modificadas no interior das embalagens têm sido sugeridos como formas de se prolongar a vida de prateleira dos "fresh-cut", preservando seus atributos de qualidade, sendo o escurecimento o fator limitante primário na conservação de bananas minimamente processadas (VILAS BOAS e KADER, 2001). O cálcio é um mineral que se liga às substâncias pécticas, dando origem aos pectatos de cálcio, estruturas que conferem estabilidade à parede celular. $\mathrm{O}$ uso de cálcio por meio de soluções aquosas de seus sais, como cloreto de cálcio e lactato de cálcio, tem sido eficaz na prevenção do amaciamento de uma série de frutas (VILAS BOAS, 2002). O ácido ascórbico e seus vários sais neutros são os principais antioxidantes para o uso em frutos e hortaliças e seus sucos, visando a prevenir escurecimento e outras reações oxidativas (WILEY, 1994). Além disso, tem aumentado o número de componentes antioxidantes estudados em frutos minimamente processados, incluindo os aminoácidos e peptídeos que contêm enxofre ( $\mathrm{SH}$ ),

\footnotetext{
1. Nutricionista, mestre em Ciência dos Alimentos, Universidade Federal de Lavras/UFLA - Caixa Postal 37 - $37200-000$ - Lavras, MG.

2. Engenheiro Agrônomo, Professor Doutor em Ciência dos Alimentos, Departamento de Ciência dos Alimentos/UFLA.

3. Zootecnista, mestrando em Ciência dos Alimentos, UFLA.

4. Engenheira de Alimentos, Professora Doutora em Ciência dos Alimentos, UFLA.
} 
como a L-cisteína (MOLNAR-PERL e FRIEDMAN, 1990; VILAS BOAS, 2002). O emprego de atmosfera modificada, em embalagens seladas, diminui significativamente o crescimento microbiano, quando comparado a embalagens comerciais convencionais não-seladas (KING JÚNIOR et al., 1991).

Rodelas de bananas são peças-chave no preparo de saladas de frutas, embora modificações na coloração original, como o escurecimento e o amaciamento, constituam fatores limitantes na comercialização de saladas que contêm bananas. Em face do exposto, objetivou-se com este trabalho avaliar o efeito da atmosfera modificada ativamente com as concentrações iniciais de $2 \%$ $\mathrm{O}_{2}+10 \% \mathrm{CO}_{2}$ e dos tratamentos químicos (L-cisteína, ácido ascórbico, cloreto de cálcio) sobre a vida de prateleira e qualidade de banana 'Prata' minimamente processada.

Foram utilizadas bananas da cultivar 'Prata', originadas do mercado local. Os frutos foram selecionados de acordo com homogeneidade e estádio de maturação (grau 5 de coloração da casca: casca amarela com pontas verdes, de acordo com Dole Bananas (1998)). Em seguida, foram transferidos para câmara fria a $8^{\circ} \mathrm{C}$ e $85 \%$ UR, por um intervalo de 24 horas, até o início do experimento. Os frutos inteiros foram lavados com água e sabão, e imersos em água gelada $\left( \pm 8^{\circ} \mathrm{C}\right)$ com $500 \mathrm{ppm}$ de hipoclorito de sódio durante quinze minutos. A seguir, foram submetidos ao descascamento e ao corte em rodelas de aproximadamente $1 \mathrm{~cm}$ de espessura. Em seguida, os frutos foram mergulhados em seus respectivos tratamentos por 3 minutos e as fatias drenadas em gaze durante 2 minutos para retirada de excesso de líquido. Terminado esse procedimento, as bananas foram acondicionadas em bandejas termoformadas de polipropileno totalizando $150 \mathrm{~g}$. As bandejas foram seladas com filme flexível de poliester + polipropileno de 60 micras; em alguns grupos, injetouse a atmosfera inicial de $10 \mathrm{kPa}$ de $\mathrm{CO}_{2}+2 \mathrm{kPa}$ de $\mathrm{O}_{2}$, utilizando-se seladora de bandejas Tec-Mac modelo AP-340. Os tratamentos foram divididos em grupos não-químicos (Controle, Atmosfera modificada ativa), grupos químicos (M1, M2 e M1+ATM):

Grupo-controle $(\mathbf{C})$ : imersão em água destilada e atmosfera modificada passiva;

Grupo atmosfera modificada ativa (ATM): água destilada + injeção inicial de $\left.10 \mathrm{kPa} \mathrm{CO}+2 \mathrm{kPa} \mathrm{O}_{2}\right)$;

Grupo M1: solução química de L-cisteína $(0,5 \%)$, ácido ascórbico (1\%) e cloreto de cálcio $(1 \%)$;

Grupo M2: solução química de L-cisteína (1\%), ácido ascórbico (1\%) e cloreto de cálcio (1\%);
Grupo M1+ATM: imersão em solução química de Lcisteína $(0,5 \%)$, ácido ascórbico $(1 \%)$ e cloreto de cálcio $(1 \%)+$ atmosfera modificada ativa já mencionada.

Análises: A perda de massa foi expressa em porcentagem, considerando-se a diferença entre a massa líquida inicial da embalagem e aquela obtida a cada intervalo de tempo de amostragem. A perda de massa foi determinada nas mesmas embalagens, ao longo do período de armazenamento. $\mathrm{O} \mathrm{pH}$ foi determinado no filtrado, de acordo com o método da AOAC (1990). A acidez total titulável (ATT) foi medida por titulação do homogenato filtrado em gaze, com $\mathrm{NaOH}$ a $0,1 \mathrm{M}$ padronizado segundo técnica estabelecida pelo Instituto Adolfo Lutz (1985), e os resultados expressos em porcentagem de ácido málico. Os sólidos solúveis totais (SST) foram determinados por refratometria, segundo a AOAC (1990), e os resultados expressos em porcentagem. Os açúcares solúveis totais (AST) foram extraídos com álcool etílico a $80 \%$ e determinados pelo método de Dische (1962). Os resultados expressos em porcentagem.

A contagem total de microrganismos aeróbios mesófilos foi realizada pelo método de plaqueamento em profundidade, usando ágar para a contagem padrão (PCA), sendo as placas incubadas a $35^{\circ} \mathrm{C}$ por 48 horas. Após o período de incubação, procedeu-se à leitura das placas, sendo os resultados expressos em Unidades Formadoras de Colônia por grama (UFC/g). A quantificação de fungos filamentosos e leveduras foi realizada pelo método de plaqueamento em superfície, utilizando o meio Batata Dextrose Agar (BDA) acidificado com ácido tartárico a $10 \%$. As placas foram incubadas a $25^{\circ} \mathrm{C}$ por 5 dias e os resultados expressos em UFC/g. Para a quantificação de coliformes a $35^{\circ} \mathrm{C}$ (totais) e $45^{\circ} \mathrm{C}$ (fecais), utilizou-se a técnica do número mais provável (NMP). O teste presuntivo foi realizado com inoculação de alíquotas da amostra em séries de três tubos contendo Caldo Lauril Sulfato Triptose (LST), incubados a $35^{\circ} \mathrm{C}$, por 48 horas e tubos contendo Caldo Escherichia Coli $(\mathrm{EC})$ incubados a $44,5^{\circ} \mathrm{C}$, por 48 horas.

$\mathrm{O}$ experimento foi conduzido em delineamento experimental inteiramente casualizado (DIC), com fatorial $3 \times 6$, ou seja, 3 tratamentos químicos (M1, M2 e M1+ATM) em 6 tempos ( 0 h, 6 h, 1, 2, 3, 4 dias) e com fatorial de 5 x 2, ou seja, 5 tratamentos (C, ATM, M1, $\mathrm{M} 2, \mathrm{M} 1+\mathrm{ATM})$ em 2 tempos (0 h e $6 \mathrm{~h}$ ) ambos com 3 repetições. Foram feitos esses fatoriais pois a partir do $1^{\circ}$ dia, somente os tratamentos químicos (M1, M2 e M1+ATM) continuaram com suas características apropriadas para o consumo. A parcela experimental foi constituída de uma bandeja $(11,5 \mathrm{~cm} \mathrm{x} \mathrm{7,5} \mathrm{cm} \mathrm{x} 6,0$ $\mathrm{cm}$ ) contendo aproximadamente $150 \mathrm{~g}$ de frutos. Os 
resultados das variáveis-respostas avaliadas foram submetidos à análise de variância; as médias de tratamentos, quando significativas, foram comparadas pelo teste de Tukey ao nível de 1 e 5\% de probabilidade; já os modelos de regressões polinomiais foram selecionados com base na significância do teste de $\mathrm{F}$ de cada modelo testado e também pelo coeficiente de determinação.

As rodelas de banana-controle e sob atmosfera modificada foram avaliadas apenas a 0 e 6 horas, após processamento mínimo, visto que já às 6 horas apresentavam-se, visualmente, impróprias para o consumo. As rodelas submetidas aos tratamentos químicos foram avaliadas por 4 dias.

Houve diferenças estatísticas significativas de perda de massa somente em função do período de armazenamento. Até as seis horas após o processamento, não houve perda de massa, já a partir do primeiro dia, iniciou-se um aumento de perda de massa até o quarto dia de armazenamento ( $\mathrm{y}=0,01$ $\left.-0,01 x+0,01 x^{2} ; R^{2}=0,98\right)$. Mesmo tendo sido observadas diferenças estatisticamente significativas ao longo do tempo, em termos práticos, a perda de massa foi mínima, atingindo o máximo de $0,13 \%$. Carvalho (2000) também observou perda de massa mínima (não chegando a $1 \%$ ) em kiwis minimamente processados armazenados a $1^{\circ} \mathrm{C}$, sob atmosfera modificada.

$\mathrm{O}$ pH não foi influenciado pelos diferentes tratamentos ao longo do armazenamento, à exceção das 6 horas, quando as fatias tratadas com misturas químicas (M2, M1 e M1+ATM) apresentaram, estatisticamente, os menores valores de $\mathrm{pH}$, comparadas com os gruposcontrole e ATM. Entretanto, em termos práticos, a diferença foi mínima, visto que os valores médios de $\mathrm{pH}$ variaram de 4,16 a 4,25 .

Diferenças estatisticamente significativas não foram observadas entre os tratamentos estudados, com relação à acidez total titulável (ATT). Entretanto, a ATT de bananas minimamente processadas foi influenciada pelo período de armazenamento (Figura 1), apresentando uma redução nas seis primeiras horas, suge- rindo um estresse imediato após o processamento, com a utilização dos ácidos como substrato para obtenção de energia. Brackman e Saquet (1995) citam que os ácidos são as substâncias mais prontamente disponíveis para obtenção de energia pela célula, pois fazem parte do ciclo de Krebs. Após seis horas do processamento, houve um acréscimo da ATT, até o quarto dia de armazenamento. Carvalho et al. (1988) obtiveram 0,257 a $0,443 \%$ de ATT, trabalhando com o mesmo fruto. Os teores médios observados neste trabalho estão entre 0,39 a $0,42 \%$, encontrando-se na faixa referida pelos autores citados.

A variável sólidos solúveis totais (SST) mostrouse afetada significativamente pelo período de armazenamento e pelos diferentes tratamentos (M2, M1 e M1+ATM), embora não tenha sido observada uma interação significativa entre esses dois fatores.

As fatias tratadas com $1 \%$ de $\mathrm{CaCl}_{2}, 1 \%$ de ácido ascórbico e $1 \%$ de L-cisteína (tratamento M2) apresentaram menores teores de SST (Figura 2), sugerindo que esse tratamento foi mais eficiente em retardar a degradação dos carboidratos complexos, quando comparado com o grupo que utilizou a mesma mistura, só que com a concentração de $0,5 \%$ de L-cisteína (M1).

Os resultados de SST do grupo tratado com a mistura química e atmosfera modificada (M1+ATM) não apresentaram diferenças dos demais tratamentos; portanto, o uso da atmosfera modificada não alterou os valores de SST, ao contrário dos resultados de Chantanawarangoon (2000), que obteve menores teores de SST utilizando atmosfera modificada $(2 \mathrm{kPa}$ $\left.\mathrm{O}_{2}+10 \mathrm{kPaCO}_{2}\right)$ em mangas minimamente processadas.

No tempo 0 e 6 horas, não foram observadas diferenças estatísticas nos valores de SST dos tratamentos; portanto, o grupo Controle e ATM não se enquadram no gráfico anterior, pois esses já nas 6 horas após o processamento não apresentavam características sensoriais aceitáveis (Figura 4). 


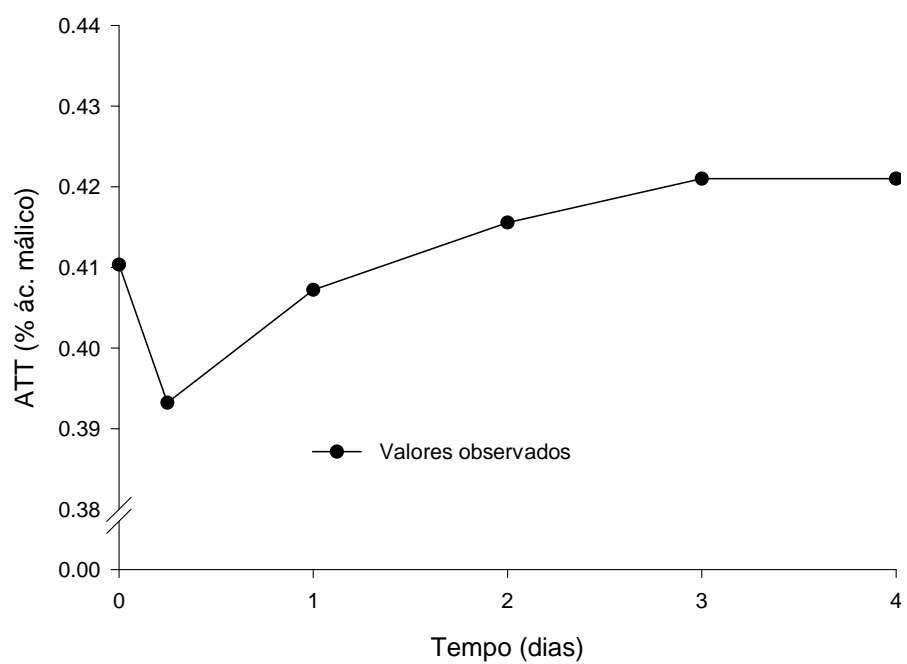

FIGURA 1 - Valores médios observados de ATT em banana 'Prata' minimamente processada submetida a diferentes tratamentos e armazenada a $8^{\circ} \mathrm{C}$, durante 4 dias.

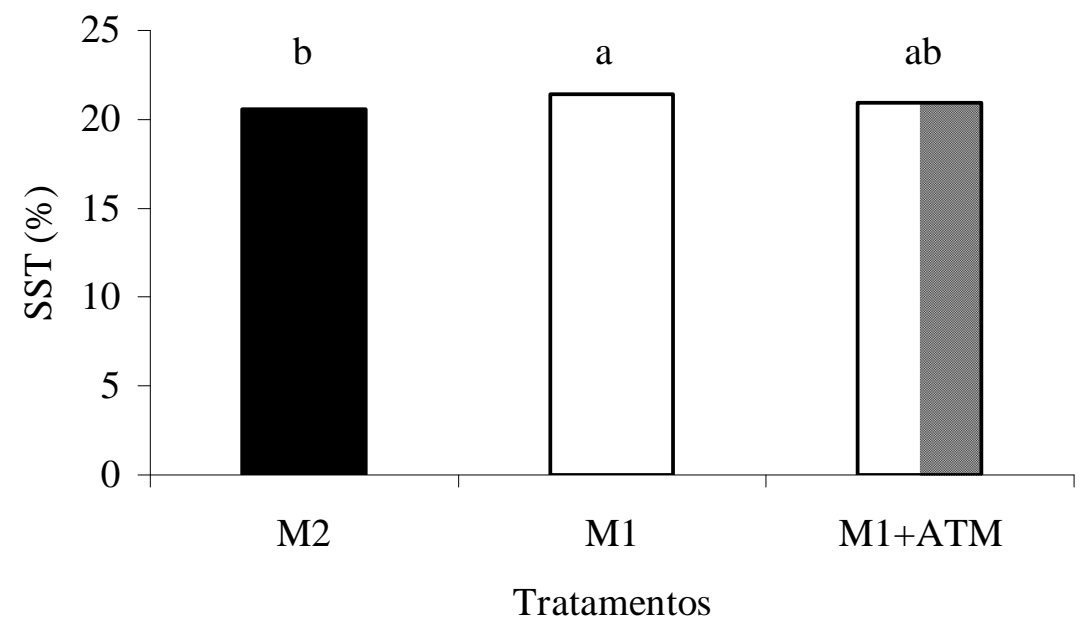

FIGURA 2 - Valores médios observados de SST em banana 'Prata' minimamente processada submetida a diferentes tratamentos, armazenada a $8^{\circ} \mathrm{C}$, durante 4 dias.

O aumento observado nos teores de SST ao longo do tempo pode relacionar-se com a degradação de polissacarídeos e, conseqüentemente, ao aumento notado nos teores de açúcares solúveis totais (Figura 3). A maior mudança quantitativa associada com o amadurecimento é a conversão de amido em açúcares (VILAS BOAS, 1999). Assim como a banana, em estudos anteriores outros frutos também apresentaram aumento de SST durante o armazenamento, entre eles o melão e a manga minimamente processados.
Diferenças significativas, para a variável açúcares solúveis totais (AST), foram detectadas somente no decorrer do tempo de armazenamento (Figura 3); portanto, o uso da atmosfera modificada e diferentes concentrações de L-cisteína (0,5 e 1,0\%) não influenciaram o comportamento dessa variável.

$\mathrm{O}$ aumento linear nos teores de AST, que pode ser associado ao aumento nos SST encontrado durante o armazenamento de bananas 'Prata', também foi observado por Vilas Boas (1995), que notou um incremento de $1 \%$ para $19 \%$ na concentração de AST com seu ama- 
durecimento. Os polissacarídeos são metabolizados a açúcares solúveis e esses aumentam durante o período de amadurecimento dos frutos. Esse processo é acelerado com o descasque, fatiamento e pelas outras etapas do processamento mínimo, justificando esse aumento de AST até o quarto dia.

Quanto aos índices microbiológicos, as contagens de fungos filamentosos, leveduras e microrganismos aeróbios mesófilos foram baixas (Figura 4), significando que as boas práticas foram respeitadas durante o processamento da matéria-prima. Para frutos e hortaliças minimamente processados, as considerações sobre microbiologia são essenciais, visto que as operações, ao longo do processamento, propiciam a exsudação de nutrientes presentes no interior dos tecidos, favorecendo o crescimento microbiológico no alimento (CANTWELL, 2000). Com os resultados obtidos neste trabalho, pode-se considerar que não houve presença de coliformes a $37^{\circ} \mathrm{C}$ e $45^{\circ} \mathrm{C}$ (contagens inferiores a
0,3 NMP/g) (Tabela 1). Não houve crescimento expressivo de microrganismos durante o período de armazenamento, e os grupos-controle e ATM apresentaram maiores números de UFC de fungos filamentosos e leveduras 6 horas após o processamento, sugerindo que os tratamentos químicos deste experimento atuaram de forma a assegurar a qualidade microbiológica do produto.

Conclui-se que a atmosfera modificada, isoladamente, não estende a vida de prateleira de bananas minimamente processadas. A perda de massa, o pH e os teores de acidez total titulável e açúcares solúveis totais não são influenciados, diferentemente, pelo nível de cisteína $(0,5$ ou $1,0 \%)$ no banho químico (cisteína $+1 \%$ ácido ascórbico $+1 \%$ cloreto de cálcio), aliado ou não à atmosfera modificada ativa. A adoção de boas práticas de fabricação é fundamental para obtenção de bananas minimamente processadas microbiologicamente seguras.

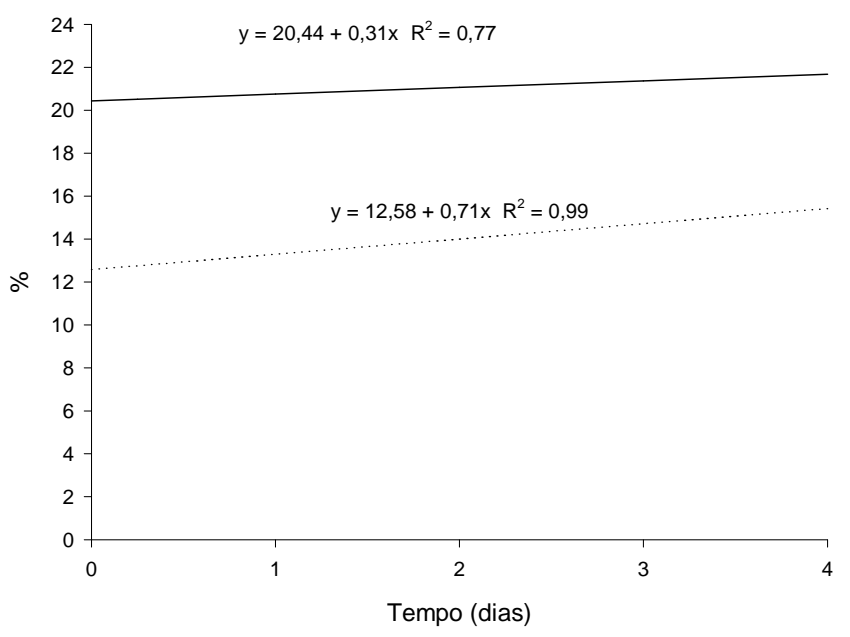

FIGURA 3 - Valores médios observados, equação de regressão e coeficiente de determinação de SST (linha sólida) e AST (linha pontilhada) em banana 'Prata' minimamente processada submetida a diferentes tratamentos e armazenada a $8^{\circ} \mathrm{C}$, durante 4 dias. 

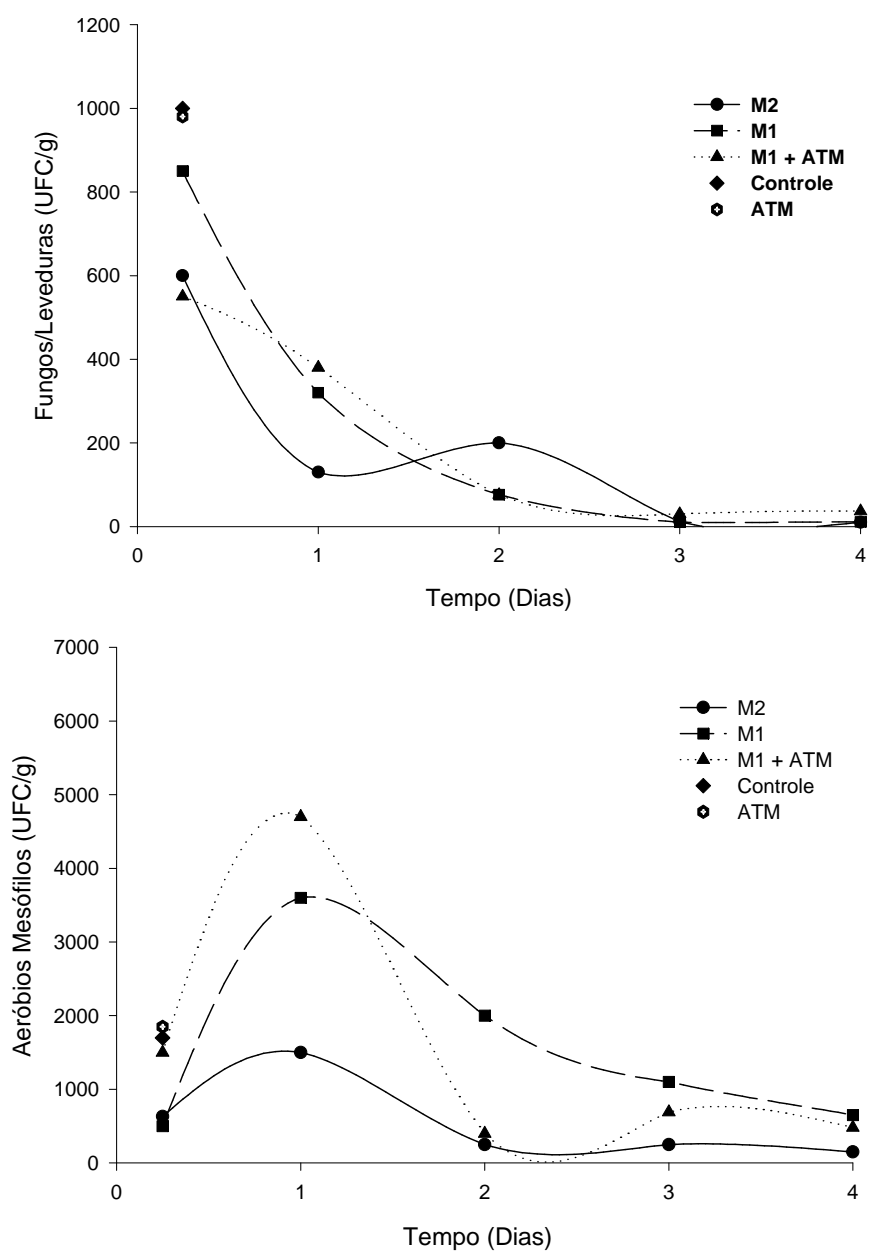

FIGURA 4 - Valores m..... los (UFC/g) em banana 'Prata' minimamente processada submetida a diferentes tratamentos armazenada a $8^{\circ} \mathrm{C}$, durante 4 dias.

TABELA 1 - Quantificação de coliformes totais e fecais em banana 'Prata' minimamente processada.

\begin{tabular}{cccccc}
\hline \multirow{2}{*}{ Tratamentos } & \multicolumn{5}{c}{ Tempo (dias) } \\
\cline { 2 - 6 } & $\mathbf{0 . 2 5}$ & $\mathbf{1}$ & $\mathbf{2}$ & $\mathbf{3}$ & $\mathbf{4}$ \\
\hline M2 & $<0,3$ & $<0,3$ & $<0,3$ & $<0,3$ & $<0,3$ \\
M1 & $<0,3$ & $<0,3$ & $<0,3$ & $<0,3$ & $<0,3$ \\
M1 + ATM & $<0,3$ & $<0,3$ & $<0,3$ & $<0,3$ & $<0,3$ \\
Controle & $<0,3$ & - & - & - & - \\
ATM & $<0,3$ & - & - & - \\
\hline
\end{tabular}




\section{REFERÊNCIAS BIBLIOGRÁFICAS}

AGÊNCIA NACIONAL DE VIGILÂNCIA SANITÁ-

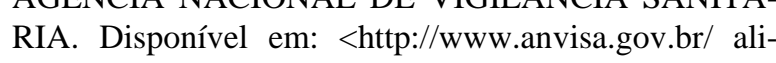
mentos/aditivo.htm>. Acesso em: 7 nov. 2003.

ASSOCIATION OF OFFICIAL AGRICULTURAL CHEMISTS. Official methods of the association of agricultural chemists. 15. ed. Washington, 1990. $2 \mathrm{v}$.

BRACKMAN, A.; SAQUET, A. A. Efeito da temperatura e condições de atmosfera controlada sobre a conservação de caqui (diospyros kaki, L.). Ciência Rural, Santa Maria, v. 25, n. 2, p. 215-218, 1995.

CANTWELL, M. The dinamic fresh-cut sector of the horticultural industry. ENCONTRO NACIONAL SOBRE PROCESSAMENTO MÍNIMO DE FRUTAS E HORTALIÇAS, 2., 2000, Viçosa. Anais... Viçosa: UFV, 2000. p. 147-155.

CARVALHO, A. V. Avaliação da qualidade de kiwis cv. 'Hayward', minimamente processados. 2000. 86 p. Dissertação (Mestrado em Ciência dos Alimentos) Universidade Federal de Lavras, Lavras, 2000.

CARVALHO, H. A.; CHITARRA, M. I. F.; CARVALHO, H. S. de; CHITARRA, A. B. Banana 'Prata' amadurecida sob umidade relativa elevada. Pesquisa Agropecuária Brasileira, Brasília, v. 23, n. 12, p. 1331-1338, 1988.

CHANTANAWARANGOON, S. Quality maintenance of fresh-cut mango cubes. Davis: University of California, 2000. $71 \mathrm{p}$.

DISCHE, Z. General color reactions. In: WHISTLER, R. L.; WOLFRAM, M. L. Carbohydrate chemistry. New York: Academic, 1962. p. 477-512.

DOLE BANANAS. Banana ripening guide. San Francisco: Dole Fresh Fruit, 1998.

INTERNATIONAL FRESH-CUT PRODUCE ASSOCIATION. 2002. Disponível em: <http://www. fresh-cuts.org>. Acesso em: 25 fev. 2003.
INSTITUTO ADOLFO LUTZ. Normas analíticas, métodos químicos e físicos para análise de alimentos. 3. ed. São Paulo, 1985. v. 52, 533 p.

KING JÚNIOR, A. D.; MAGNUSON, J. A.; TOROK, T.; GOODMAN, N. Microbial flora and storage quality of partially processed lettuce. Journal of Food Science, Chicago, v. 56, n. 2, p. 459-461, 1991.

MOLNAR-PERL, I.; FRIEDMAN, M. Inhibition of browning by sulfur amino acids: 3 . apples and potatoes. Journal Agriculture Food Chemistry, Chicago, v. 38, p. $1652-1656,1990$.

SHEWFELT, R. L. Postharvest treatment for extending the shelf life of fruits and vegetables. Food Technology, Chicago, p. 70-78, May 1986.

VILAS BOAS, E. V. de B. Aspectos fisiológicos do desenvolvimento de frutos. Lavras: UFLA/FAEPE/ DCA, 1999. $71 \mathrm{p}$.

VILAS BOAS, E. V. de B. Modificações póscolheita de bananas 'prata' (Musa acuminata X Musa balbisiana Grupo AAB) $\gamma$-irradiada. 1995. 73 f. Dissertação (Mestrado em Ciência dos Alimentos) - Universidade Federal de Lavras, Lavras, 1995.

VILAS BOAS, E. V. de B. Tecnologia de processamento mínimo de banana, mamão e kiwi. In: SEMINÁRIO INTERNACIONAL DE PÓS-COLHEITA E PROCESSAMENTO MÍNIMO DE FRUTAS E HORTALIÇAS, 2002, Piracicaba. Anais... Piracicaba: ESALQ, 2002. p. 1-7.

VILAS BOAS, E. V. de B.; KADER, A. A. Effect of 1MCP on fresh-cut fruits. Perishables Handling Quarterly, Davis, n. 108, p. 25, Nov. 2001.

WILEY, R. C. Minimally processed refrigerated fruits and vegetables. London: Chapman \& Hall, 1994. $357 \mathrm{p}$. 